\title{
The effects of conceptual training on reversal shift performance of young children*
}

\author{
THOMAS J. FAGAN and ALLAN H. SCHULMAN $\dagger$ \\ Virginia Polytechnic Institu te and State University, Blacksburg, Virginia 24061
}

\begin{abstract}
The relationship between conceptual training (analytic vs nonanalytic) and performance on a reversal shift task was studied in 4-, 6-, and 8-year-old children. Results revealed: (1) with increasing age, reversal shift performance improved; (2) only 6-year-old children showed a stable conceptual style; and (3) while both types of training enhanced reversal performance, analytic training resulted in greater facilitation of reversal shift learning. It was concluded that conceptual training channels a S's attention upon the relevant dimensions of the shift task.
\end{abstract}

Kendler and Kendler (1962) have found that, with increasing chronological age, reversal shifts become easier to master and suggest that the development of verbal mediators facilitates such reversal shift performance (Kendler, 1964). Since verbal mediation is a covert process, attention must be given to a person's covert ability to perceptually organize and conceptually categorize stimuli from his external environment Kagan, Moss, and Siegel (1963) have termed this process "conceptual style." Kagan, Rosman, Day, Albert, and Phillips (1964) have isolated two general types of developmentally related conceptual styles. The relational or nonanalytic conceptual response is one in which a functional relationship, established among stimulus class members, becomes the basis for grouping the members. The analytic conceptual response is one in which a visible element shared by all class members is used as the basis for defining the group.

The nonanalytic response, considered to involve the least amount of discriminatory ability, is hypothesized by Hess and Shipman (1965) to occur most frequently in preschool children. With development, analytic responding becomes more prevalent. Moreover, it has been shown by Kagan et al (1963) that analytic children show more verbal labeling than nonanalytic children. Since both conceptual style and reversal shift studies report overt verbal labeling at approximately the same age, this suggests the possibility that a good deal of overlap is occurring between the two processes.

If reversal shift performance and conceptual development are not unrelated psychological processes, one might predict that an experimentally produced change in conceptual style should result in a change in reversal shift performance.

\section{METHOD}

\section{Subjects}

Ss were 135 white middle class children from the Blacksburg,

*This report is based upon a thesis submitted by the first author to Virginia Polytechnic Institu te and State University in partial fulfillment of the requirements for the master's degree.

tRequests for reprints should be sent to Allan H. Schulman

Department of Psychology, Virginia Polytechnic Institute and State University, Blacksburg, Virginia 24061
Virginia area. Forty-five of these Ss had a mean age of 4 years 8 months ( 26 females and 19 males), another 45 had a mean age of 6 years 4 months ( 22 females and 23 males), and the remaining 45 Ss had a mean age of 8 years 6 months ( 20 females and 25 males).

\section{Apparatus}

The apparatus consisted of a baseboard $(30.48 \times 40.64 \mathrm{~cm})$ mounted on a swivel base and divided in half by a perpendicular board $20.32 \mathrm{~cm}$ high and $30.48 \mathrm{~cm}$ wide. On each half of the baseboard were two, evenly spaced, felt-padded depressions.

\section{Procedure}

The stimuli used in both initial and reversal shift learning were two hemispheres $7.6 \mathrm{~cm}$ in diameter and two hemispheres $5.7 \mathrm{~cm}$ in diameter. One of the large and one of the small hemispheres were painted black and the remaining two hemispheres were painted white. For half of the Ss in each age group tested, black was the rewarded choice. For the remaining half of each age group, white was the rewarded choice. A marble placed in one of the depressions served as the token reward. Ss were randomly assigned to these two reward contingencies. Stimulus pairs presented were: large black, small white; large white, small black; small black, large white; and small white, large black. These four pairs were presented in random order. The instructions given to each $S$ at the start of the prereversal and reversal shift learning were slightly modified from Kendler and Kendler (1959) to facilitate the use of three-dimensional stimuli.

When Ss from each age group met a criterion of 9 out of 10 correct choices on initial learning, they were matched on their trials-to-criterion score for initial learning and placed in one of three groups of $15 \mathrm{Ss}$ each. One group received analy tic training; another received nonanaly tic training; and the third group served as a control group, receiving no training task. Stimuli used for training were three-dimensional objects familiar to the Ss. On each training trial, Ss were shown a test object and then presented with two additional stimulus objects, one of which was related to the test objects along an elemental or analytical dimension and the other of which was related to the test object along a relational or nonanalytic dimension. Ss were asked to judge which of the two stimulus objects was most similar to the test object. Ss were reinforced with a marble if they responded in accordance with their training condition.

The criterion for training was a correct response accompanied by a correct verbal reason for the choice on each of 15 different stimulus presentations.

Control Ss were read a story for a period of $10 \mathrm{~min}$. After the story, or for experimental Ss, after the training criterion has been met, a reversal shift procedure was instituted. For this task, the response alternative opposite to that which was previously rewarded in initial learning was the correct choice. 
Table 1

Mean Trials to Criterion Scores for Nine Groups of Children (4, 6, and 8 Years of Age) on Initial Learning, Conceptual Training, and Reversal Shift Performance

\begin{tabular}{llccc}
\hline Age & $\begin{array}{c}\text { Training } \\
\text { Condition }\end{array}$ & $\begin{array}{c}\text { Initial } \\
\text { Learning }\end{array}$ & Training & $\begin{array}{c}\text { Reversal } \\
\text { Shift } \\
\text { Learning }\end{array}$ \\
\hline \multirow{4}{*}{ 4 Years } & Analytic & 26.9 & 17.3 & 16.6 \\
& Nonanalytic & 26.5 & 17.2 & 23.7 \\
& Control & 26.7 & - & 26.8 \\
& Analytic & 28.5 & 17.8 & 13.3 \\
6 Years & Nonanalytic & 28.4 & 16.1 & 14.9 \\
& Control & 28.4 & - & 22.1 \\
& Analytic & 19.1 & 16.9 & 11.1 \\
8 Years & Nonanalytic & 19.4 & 16.0 & 12.4 \\
& Control & 18.9 & - & 16.2 \\
\hline
\end{tabular}

\section{RESULTS}

Table 1 summarizes the results of the three phases of the study. At no point of the study were reliable sex differences in responding observed.

\section{Initial Learning}

Since Ss within each treatment for each age group were matched for initial learning, only a significant age difference was observed during initial learning $(F=4.21$, $\mathrm{df}=2 / 99, \mathrm{p}<.025)$. Duncan's test revealed reliable differences in performance between 6- and 8-year-old Ss $(\mathrm{p}<.05)$.

\section{Training}

A summary of mean trials-to-criterion scores for Ss receiving analytic and nonanalytic training can also be found in Table 1. An analysis of variance revealed a significant age effect for only those Ss receiving nonanalytic training $(\mathrm{F}=3.53, \mathrm{df}=2 / 33, \mathrm{p}<.05)$. A Duncan's test, contrasting each age level tested, showed that 4-year-old children took significantly longer than either 6- or 8-year-old children to reach criterion on nonanalytic training $(\mathrm{p}<.05)$.

The initial choice given by Ss in each age group during the first trial of cognitive trianing was used as a rough estimate of the S's conceptual style before such a preference was subjected to experimental manipulation. Statistical evaluation for this data revealed no consistent cognitive preference among 4-year-olds or 8-year-olds. Six year-old Ss, however, tended to be significantly nonanalytic in their initial responses $\left(\chi^{2}=8.53\right.$, $p<.05)$. Although at the end of training all Ss were responding in accordance with their training conditions, only 6-year-old Ss showed a significant change from their initial training response preference $\left(\chi^{2}=8.53\right.$, $\mathrm{p}<.05)$.

\section{Reversal Shift Learning}

Table 1 shows mean trials-to-criterion scores during reversal shift learning. When these scores were submitted to an analysis of variance, significant differences were noted among ages $(\mathrm{F}=4.82, \mathrm{df}=2 / 99, \mathrm{p}<.025)$ and training $(F=4.266, d f=2 / 99, p<.025)$. Subsequent analyses with Duncan's test revealed that: (1) 8-year-old Ss performed reliably better than 6-year-old Ss $(\mathrm{p}<.05)$ who performed reliably better than 4-year-old Ss on reversal shift learning $(\mathrm{p}<.05)$, and $(2)$ analytic training produced significantly faster reversal shift learning than did nonanalytic training $(\mathrm{p}<.05)$, and nonanalytic training produces significantly faster reversal shift learning than did the control condition $(\mathrm{p}<.05)$.

\section{DISCUSSION}

With age, the child's discriminative abilities are said to sharpen to the point where similarities between objects are judged analytically on the basis of their component parts. Kagan has observed that this analytic preference becomes a relatively stable response by approximately 8 years of age. Two results of the training phase of the present study failed to demonstrate a systematic age-related change from nonanalytic to analytic responding. First, using initial training responses we found 6-year-old Ss to be more nonanaly tic than either 4- or 8-y ear-old S. However, it should be emphasized that initial response may not be an adequate measure of conceptual style. Additionally, trials-to-criterion scores during training revealed that 6-year-old Ss took longer than either 4- or 8-year-old Ss to master the analytic training task further suggesting that 6-year-old Ss were initially the most nonanalytic.

The hypothesis that analytic training would facilitate reversal shift learning was confirmed. However, nonanaly tic training was also found to facilitate reversal shift performance. One possible explanation of this finding is that both types of training gave Ss additional practice at isolating relevant dimensions in a given stimulus complex (i.e., the overtraining reversal effect). Support for this explanation has been found by a number of researchers (Eimas, 1966; Lowenkron \& Driessen, 1971). Moreover, Ss in both training groups were asked to verbalize their reasons for choosing the dimension which they did. Such verbalization may also have aided the S's ability to attend to relevant stimulus dimensions during reversal shift learning.

Kendler and Kendler (1962) and Kendler (1970) have proposed a three-stage, age-related hierarchy of development which is integrally related to the child's ability to verbalize relevant stimulus dimensions. They have noted that by the time a child is 8 years old, he readily assigns covert verbal labels to his discriminative actions and thereby has little difficulty in performing reversal shifts. In the present study, the finding that with increasing age (Table 1) the number of trials needed to reach reversal shift criterion decreased, would appear at least superficially to lend support to this theory. Six-year-old Ss showed the greatest improvement between initial and reversal learning (Table 1). Kendler (1964) found that by requiring 5and 6-year-olds to say a sentence labeling the positive and negative stimuli of the relevant dimension, initial learning was facilitated and the proportion of children making subsequent reversal shifts was increased. Either type of training in the present experiment could easily have served this same function. One would not expect training effects upon 8-year-old Ss to be as pronounced since they are already capable of verbal mediation. Four-year-old children were found to show only a marginal amount of improvement between initial and reversal shift learning. However, since 4-year-old children are, theoretically, only beginning to develop verbal mediating abilities, training of the rather modest duration provided in this experiment would not be expected to produce an overwhelming facilitative effect. 


\section{REFERENCES}

Eimas, P. D. Effects of overtraining, irrelevant stimuli and training task on reversal discrimination learning in children. Journal of Experimental Child Psychology, 1966, 3, 315-323.

Hess, R. D., \& Shipman, V. C. Early experience and the socialization of cognitive modes in children. Child Development, 1965, 36, 869-886.

Kagan, J., Moss, H. A., \& Siegel, I. E. Psychological significance of styles of conceptualization. Monograph of Society for Research in Child Development, 1963, 28, 73-112.

Kagan, J., Rosman, B. L., Day, D., Albert, J., \& Phillips, W. Information processing in the child: Significance of analytic and reflective attitudes. Psychological Monographs, 1964, 78, 1-37.

Kendler, T. S. Verbalization and optional reversal shifts among kindergarten children. Journal of Verbal Learning \& Verbal Behavior, 1964, 3, 428-436.

Kendler, T. S. Development of mediating responses in children.
In P. H. Mussen, J. J. Conger, and J. Kagan (Eds.), Readings in child development and personality. New York: Harper \& Row, 1970.

Kendler, H. H., \& Kendler, T. S. Reversal and nonreversal shifts in kind ergarten children. Journal of Experimental Psychology, $1959,58,56-60$.

Kendler, H. H., \& Kendler, T. S. Vertical and horizontal processes in problem solving. Psychological Review, 1962, 69, 1-16.

Lowenkron, B., \& Briessen, E. C. Solution mode in concept identification problems and magnitude of the overlearning reversal effect. Journal of Experimental Psychology, 1971, 89, 85-91.

\title{
Verbal-discrimination learning as a function of encoding variability
}

\author{
JOHN H. MUELLER, EDWARD J. PAVUR, and ROBERT M. YADRICK \\ University of Missouri, Columbia, Missouri 65201
}

\begin{abstract}
The encoding variability of the right (R) and wrong (W) terms was manipulated in a verbal-discrimination task. When the number of different associates defined variability, pairs with low-encoding variability for both $R$ and $W$ terms were learned fastest, followed by pairs with high-encoding variability in both $R$ and $W$ terms. When the number of dictionary meanings defined variability, pairs with high-encoding variability $R$ terms and $W$ terms were learned slower than all other combinations. The outcomes do not correspond to expectations involving only the number of encodings in each component of a pair; it is suggested that the number of nonoverlapping encodings is more important.
\end{abstract}

The frequency theory of verbal-discrimination learning (VDL) assumes that Ss utilize a subjective difference in the frequency of experience for the right $(R)$ and wrong (W) terms in each pair in the list (Ekstrand, Wallace, \& Underwood, 1966). The evidence in support of the basic tenets of the theory is impressive (cf. Wallace, 1972). The present research is concerned with an aspect of VDL not thoroughly considered to this point, namely the encoding variability of the items in the pairs.

Frequency theory assumes that the S's experiences, e.g., perceiving, pronouncing, rehearsing, etc., accumulate as the $S$ attends to either the $\mathrm{R}$ term or $\mathrm{W}$ term in each pair. However, to the extent that the pair units may be perceived or encoded differently on separate occasions, these experiences may not accrue to the same encoding each time. If experiences for each encoding are, in fact, treated independently (rather than additively) in choosing a response, then the expectations of frequency theory would vary somewhat depending upon this aspect of the materials. This basic interpretation follows from a feature analysis of VDL (e.g., Kausler, 1973, 1974), but it also follows from frequency theory if one grants the common distinction between nominal and functional stimuli.

The basic encoding-variability hypothesis suggests several predictions for variation in the number of encodings in $\mathrm{R}$ terms and $\mathrm{W}$ terms. First, $\mathrm{R}$ terms with several possible encodings would have their experiences 